Case Reports in
Gastroenterology
Case Rep Gastroenterol 2021;15:195-201

DOI: $10.1159 / 000511286$

Published online: February 17, 2021

(C) 2021 The Author(s)

Published by S. Karger AG, Basel

www.karger.com/crg

This article is licensed under the Creative Commons Attribution-NonCommercial 4.0 International License (CC BY-NC) (http://www.karger.com/Services/OpenAccessLicense).

Usage and distribution for commercial purposes requires written permission.

\title{
Autoimmune Pancreatitis after a Seven-Year History of Suspicious Pancreatic Cancer
}

\author{
Erhan Ergin Nevin Oruc Ömer Özütemiz \\ Gastroenterology Department, Faculty of Medicine, Ege University, Izmir, Turkey
}

\section{Keywords}

Autoimmune pancreatitis · Pancreatic cancer

\begin{abstract}
In this case report, we present a case of autoimmune pancreatitis (AIP) diagnosis in a patient after a 7-year history of suspicious pancreatic cancer. Kim's and Japanese criteria were used to diagnose AIP. Our case avoided undesirable invasive procedures and recovered thanks to the proper diagnosis and timely treatment with prednisone. Early and accurate diagnosis of AIP, in this case, had a significant impact on the treatment and prognosis process.
\end{abstract}

(C) 2021 The Author(s)

Published by S. Karger AG, Basel

\section{Introduction}

Autoimmune pancreatitis (AIP) is a chronic inflammation identified by a distributed abnormal contraction of the main pancreatic duct, distributed expansion of the pancreas, antibodies, raised levels of serum gamma globulin or IgG, pancreas fibrosis, and critical lymphoplasmacytic infiltration [1-3]. The AIP concept was first introduced in 1995 by Yoshida et al. [4] and has since been widely accepted. The radiographic presentation and clinical diagnostic of AIP can simulate pancreatic ductal adenocarcinoma $[1,4]$. The differentiation with neoplasm is usually done via analysis of pathologic specimens following surgical resection [5]. Some investigators have claimed that in all patients diagnosed with a pancreatic lesion, serum

\begin{tabular}{|c|c|}
\hline$r$ & $\begin{array}{l}\text { Erhan Ergin } \\
\text { Gastroenterology Department, Faculty of Medicine, Ege University } \\
\text { TR-35040 Bornova, Izmir (Turkey) } \\
\text { drerhanergin@gmail.com }\end{array}$ \\
\hline
\end{tabular}




\section{Case Reports in Gastroenterology}

Case Rep Gastroenterol 2021;15:195-201 DOI: 10.1159/000511286

c) 2021 The Author(s). Published by S. Karger AG, Basel www.karger.com/crg

Ergin et al.: Autoimmune Pancreatitis after a Seven-Year History of Suspicious Pancreatic Cancer

IgG4 examination is necessary. For questions about the coexistence of both diseases, there are not enough data. In this report, a rare case of a patient is presented with histologically diagnosed and treated pancreatic cancer and after 7-year clinically diagnosed AIP.

\section{Case Presentation}

A 58-year-old male patient was referred to another medical center due to complaints of exhaustion, tiredness, and fever 7 years earlier. An ultrasound scan was performed; tumor formation was detected on the pancreatic head, and severe stenosis was detected in the choledochal and pancreatic tract by ERCP. A plastic stent was placed into the choledochal tract. A biopsy was performed, and inflammatory changes as well as lymphoplasmacytic infiltration were detected on the papilla of Vater; however, fine needle aspiration biopsy of the pancreatic papilla revealed a suspected mucinous cystic adenocarcinoma of the pancreas. Cytopathology slides of the patient were re-evaluated and the diagnosis was confirmed. He was considered inoperable because of the invasion of the superior mesenteric artery detected by CT scan, and chemotherapy and simultaneous radiotherapy were performed. There was no mass in the pancreas in the control CT scans during follow-up. The patient had recurrent cholangitis attacks because of sclerosing cholangitis, and a metallic stent was placed in another medical center.

The patient was referred to our clinic because of suspected jaundice and bleeding in the 6th year of follow-up. Autoimmune markers were normal; no pancreatic mass was detected by MRI, but pancreatic atrophy was observed. Since the patient had shown no change in the 7-year survey and previous biopsies had indicated benign and inflammatory changes except for one biopsy, OP was considered rather than pancreatic cancer. Pancreatic atrophy, sclerosing cholangitis, mediastinal lymphadenopathy, and Hashimoto thyroiditis detected in the patient are considered OP findings. Prednisolone $40 \mathrm{mg} /$ day was started, and the dose was decreased gradually every week. The patient's complaints decreased, lymphadenopathy regressed, and improvement was detected in all biochemical tests.

\section{Discussion}

AIP is a type of chronic pancreatitis that causes dysfunction in organs through fibrosis and severe lymphocytic infiltration in autoimmune inflammation $[1,6]$. Today, the number of patients diagnosed with AIP is increasing, and this complication is considered to be a universal complication that has its own clinical, radiographic, histopathologic, and serological features $[7,8]$. The exact AIP incidence is unknown, but an approximation of $5-6 \%$ of chronic pancreatitis is estimated for its prevalence $[5,9,10]$. Reports indicate that the proportion of this complication in men compared to women is $2-5: 1$, and the average age is 55 years at the time of diagnosis [2]. Clinical signs of this complication may include weight loss, mild epigastric pain, and progressive or intermittent jaundice $[5,11]$. About half of AIP patients have been reported to have diabetes mellitus [2,9]. Besides, other concomitant autoimmune diseases, such as primary sclerosing cholangitis, rheumatoid arthritis, and Sjögren syndrome, have been reported [5,12]. Previous studies have shown that in AIP patients, in addition to having antibodies such as ASMA, anti-lactoferrin, rheumatoid factor, anti-carbonic anhydrase, and ANA, serum levels of gamma-globin, IgG4, and IgG are also increased $[2,6,12]$. Therefore, the

\section{Karger'=}




\section{Case Reports in Gastroenterology}

Case Rep Gastroenterol 2021;15:195-201 DOI: 10.1159/000511286

c) 2021 The Author(s). Published by S. Karger AG, Basel www.karger.com/crg

Ergin et al.: Autoimmune Pancreatitis after a Seven-Year History of Suspicious Pancreatic Cancer

IgG4 level is used as one of the important features to find AIP, having high sensitivity and specificity $[2,13]$.

Imaging evaluation plays a critical role in diagnosing AIP; it is often the first investigative modality that raises the possibility of AIP $[14,15]$. CT imaging usually shows the following symptoms for AIP: (1) a capsule-like uniform low-density rim encircling the pancreas, (2) dispersed pancreas inflammation, (3) prolonged increase of pancreatic parenchyma, and (4) lack of intraductal stones and pancreatic calcification. Figures 1 and 2 show the mass image on the pancreatic head detected by abdominal CT and MRI performed in 2003.

The signs of ERCP include the segmental, focal, or scattered contraction of the main pancreatic duct. It has also been reported that the extrahepatic biliary duct was expanded, and the intrapancreatic portion of the common bile duct also gets contracted. MRCP, as a noninvasive imaging technique, is used in the diagnosis of AIP $[5,16]$ and also can precisely assess the pancreatic ducts and the biliary tree [17].

In our case, the initial imaging features on CT and MRCP suggested the presence of AIP with an enlarged pancreatic head. Histopathologic AIP analyses indicated a significant appearance of plasma cell infiltration in the surrounding medium, large interlobular ducts, lymphocytes, acinar atrophy, and dense fibrosis specimens $[2,5]$.

Since AIP is difficult to distinguish from other forms of pancreatic carcinoma and chronic pancreatitis, a variety of diagnostic criteria have been proposed $[6,9,18,19]$. As Kim's and Japanese criteria focus on imaging studies [1], they are often used for practical purposes. In these criteria, a patient who first meets criterion 1 and then each of criteria 2 to 5 is diagnosed with AIP: (1) imaging criteria: segmental or dispersed abnormal contraction of the main pancreatic duct and dispersed expansion of the pancreas (essential); (2) laboratory criteria: raised levels of IgG4 and/or IgG, or presence of autoantibodies; (3) histopathologic criteria: lymphoplasmacytic and fibrosis infiltration; (4) correlation with other autoimmune disorders; (5) response to steroid therapy.

As our case had criteria 1, 3, and 5, AIP was diagnosed. The first-line agent for AIP treatment is prednisone, which is usually initiated at a dose of $0.4-0.6 \mathrm{mg} / \mathrm{kg} /$ day for months. Patients are regularly administered for 2-3 months, with a $5 \mathrm{mg}$ tapering schedule for every $2-$ 4 weeks. Ultimately, prednisone is stopped or maintained at a dose of $2.5-10 \mathrm{mg} /$ day $[6,20]$. The steroid response is interpreted as a consequence of a negative transformation of detected autoantibodies, an improvement in clinical symptoms, a lack of abnormal pancreatic imaging, and normalization of elevated IgG levels. Prednisone of the mentioned dose led to a very good treatment response in our case. Our patient avoided undesirable invasive procedures and recovered thanks to the proper diagnosis and timely treatment with prednisone. Figure 3 shows the metallic stent image and atrophic pancreas appearance that were detected in the CT scan taken in 2010.

Although synchronous cases of AIP and pancreatic cancer have been reported [21, 22], the reverse relationship is not clear. AIP may also predispose to the development of pancreatic cancer. Kamisawa et al. [23] found a significant percentage of K-ras mutation in the pancreas of all patients with AIP. AIP can be a risk factor of pancreaticobiliary cancer. This case may have developed AIP following pancreatic cancer, or the patient may have been mistakenly diagnosed with pancreatic cancer instead of AIP. Beyond a histological diagnosis during the first evaluation, there was no evident malignant lesion in the pancreas, both in histological analysis and imaging studies. However, the inflammatory changes which possibly appeared due to celiac disease were accepted as an invasion of pancreatic cancer, and chemotherapy as well as

\section{Karger'=}




\section{Case Reports in Gastroenterology}

\begin{tabular}{l|l}
\hline Case Rep Gastroenterol 2021;15:195-201 \\
\hline DOI: 10.1159/000511286 & $\begin{array}{l}\text { ○ 2021 The Author(s). Published by S. Karger AG, Basel } \\
\text { www.karger.com/crg }\end{array}$ \\
\hline
\end{tabular}

Ergin et al.: Autoimmune Pancreatitis after a Seven-Year History of Suspicious Pancreatic Cancer

radiotherapy were performed due to the diagnosis of inoperable pancreatic cancer. Given the whole chronological process, we believe that our case had AIP from the beginning.

This case provided valuable information about the long-term progress and changes in AIP, followed by any therapy. The pancreas progresses to atrophy during follow-up while autoantibodies become negative in the long term. In this case, it was not possible to show IgG4positive cells in the affected organs because of technical incompetence. However, as mentioned in the case, histopathologic analysis showed presence of lymphoplasmacytic infiltration 7 years earlier. Figure 4 shows the changes in total and direct bilirubin levels after steroid administration between 2003 and 2010 .

Furthermore, it is difficult to evaluate the progress of autoimmune cholangiopathy concomitant to AIP because a metallic stent was not placed in the case. However, a significant decrease in bilirubin values of the case after steroid treatment would suggest that autoimmune cholangiopathy does not remit spontaneously during the progress of AIP, but also responds well to steroids. In this case, persistent cholangitis attacks as well as disruption of biliary drainage despite the metallic stent caused the development of secondary biliary cirrhosis. Esophageal varicose veins and portal hypertension developed as a complication. Although this is not directly associated with AIP, it is a secondary complication that may appear in the long run. Mediastinal lymphadenopathy, abdominal lymphadenopathy, and ascites were detected in this case. These findings recovered after steroid administration. Figure 5 shows the changes in transaminase and cholestasis levels after steroid administration between 2003 and 2010.

In conclusion, AIP is a type of chronic pancreatitis with distinct radiological, clinical, serological, and histopathologic characteristics. It needs further studies, such as its association with other autoimmune diseases, pancreatic cancer, the long-term prognosis, and the precise pathogenesis. Awareness and diagnosis of this disease are very crucial because if AIP is mistaken for pancreatic cancer or ordinary chronic pancreatitis, wrong treatments such as chemotherapy or pancreatic resection may be used instead of steroid therapy. A timely and accurate diagnosis of AIP can have a significant impact on the treatment and prognosis process.

\section{Statement of Ethics}

This research complied with the guidelines for human studies; the authors herewith state that the research was conducted ethically in accordance with the World Medical Association Declaration of Helsinki. Written informed consent for publication (including images) was received from the patient.

\section{Conflict of Interest Statement}

The authors have no conflicts of interest to declare.

\section{Funding Sources}

The authors have no funding sources.

\section{Karger'}




\section{Case Reports in Gastroenterology}

\begin{tabular}{l|l}
\hline DOI: 10.1159/000511286 & (c) 2021 The Author(s). Published by S. Karger AG, Basel
\end{tabular}
www.karger.com/crg

Ergin et al.: Autoimmune Pancreatitis after a Seven-Year History of Suspicious Pancreatic Cancer

\section{Author Contributions}

E. Ergin: corresponding author, diagnosis, writing of the report. N. Oruc: co-author, diagnosis, following of the case. Ö. Özütemiz: co-author, diagnosis, following of the case. All authors approved the final version of the manuscript.

\section{References}

1 Lin LF, Huang PT, Ho KS, Tung JN. Autoimmune chronic pancreatitis. J Chin Med Assoc. 2008 Jan;71(1): $14-22$.

2 Okazaki K, Uchida K, Matsushita M, Takaoka M. Autoimmune pancreatitis. Intern Med. 2005 Dec;44(12): 1215-23.

3 Pickartz T, Mayerle J, Lerch MM. Autoimmune pancreatitis. Nat Clin Pract Gastroenterol Hepatol. 2007 Jun;4(6):314-23.

4 Yoshida K, Toki F, Takeuchi T, Watanabe S, Shiratori K, Hayashi N. Chronic pancreatitis caused by an autoimmune abnormality. Proposal of the concept of autoimmune pancreatitis. Dig Dis Sci. 1995 Jul; 40(7):1561-8.

5 Song Y, Liu QD, Zhou NX, Zhang WZ, Wang DJ. Diagnosis and management of autoimmune pancreatitis: experience from China. World J Gastroenterol. 2008 Jan;14(4):601-6.

6 Kim KP, Kim MH, Kim JC, Lee SS, Seo DW, Lee SK. Diagnostic criteria for autoimmune chronic pancreatitis revisited. World J Gastroenterol. 2006 Apr;12(16):2487-96.

7 Sutton R. Autoimmune pancreatitis - also a Western disease. Gut. 2005 May;54(5):581-3.

8 Kim KP, Kim MH, Lee SS, Seo DW, Lee SK. Autoimmune pancreatitis: it may be a worldwide entity. Gastroenterology. 2004 Apr;126(4):1214.

9 Pearson RK, Longnecker DS, Chari ST, Smyrk TC, Okazaki K, Frulloni L, et al. Controversies in clinical pancreatology: autoimmune pancreatitis: does it exist? Pancreas. 2003 Jul;27(1):1-13.

10 Okazaki K. Autoimmune pancreatitis: etiology, pathogenesis, clinical findings and treatment. The Japanese experience. JOP. 2005 Jan;6(1 Suppl):89-96.

11 Kamisawa T, Satake K. Clinical management of autoimmune pancreatitis. Adv Med Sci. 2007;52:61-5.

12 Okazaki K, Uchida K, Fukui T. Recent advances in autoimmune pancreatitis: concept, diagnosis, and pathogenesis. J Gastroenterol. 2008;43(6):409-18.

13 Kamisawa T, Imai M, Egawa N, Tsuruta K, Okamoto A. Serum IgG4 levels and extrapancreatic lesions in autoimmune pancreatitis. Eur J Gastroenterol Hepatol. 2008 Dec;20(12):1167-70.

14 Yang DH, Kim KW, Kim TK, Park SH, Kim SH, Kim MH, et al. Autoimmune pancreatitis: radiologic findings in 20 patients. Abdom Imaging. 2006 Jan-Feb;31(1):94-102.

15 Manfredi R, Graziani R, Cicero C, Frulloni L, Carbognin G, Mantovani W, et al. Autoimmune pancreatitis: CT patterns and their changes after steroid treatment. Radiology. 2008 May;247(2):435-43.

16 Cong GN, Qin MW, You H, Liu W, Xu K. Imaging features of autoimmune pancreatitis. Zhongguo Yi Xue Ke Xue Yuan Xue Bao. 2008 Aug;30(4):479-84. Chinese.

17 Calculli L, Pezzilli R, Fiscaletti M, Casadei R, Brindisi C, Gavelli G. Exocrine pancreatic function assessed by secretin cholangio-Wirsung magnetic resonance imaging. Hepatobiliary Pancreat Dis Int. 2008 Apr;7(2): 192-5.

18 Okazaki K, Kawa S, Kamisawa T, Naruse S, Tanaka S, Nishimori I, et al.; Research Committee of Intractable Diseases of the Pancreas. Clinical diagnostic criteria of autoimmune pancreatitis: revised proposal. J Gastroenterol. 2006 Jul;41(7):626-31.

19 Chari ST, Smyrk TC, Levy MJ, Topazian MD, Takahashi N, Zhang L, et al. Diagnosis of autoimmune pancreatitis: the Mayo Clinic experience. Clin Gastroenterol Hepatol. 2006 Aug;4(8):1010-6; quiz 934.

20 Kamisawa T, Satake K. Therapeutic strategy for autoimmune pancreatitis. Adv Med Sci. 2008;53(2):145-8.

21 Inoue H, Miyatani H, Sawada Y, Yoshida Y. A case of pancreas cancer with autoimmune pancreatitis. Pancreas. 2006 Aug;33(2):208-9.

22 Witkiewicz AK, Kennedy EP, Kennyon L, Yeo CJ, Hruban RH. Synchronous autoimmune pancreatitis and infiltrating pancreatic ductal adenocarcinoma: case report and review of the literature. Hum Pathol. 2008 Oct;39(10):1548-51.

23 Kamisawa T, Tsuruta K, Okamoto A, Horiguchi S, Hayashi Y, Yun X, et al. Frequent and significant K-ras mutation in the pancreas, the bile duct, and the gallbladder in autoimmune pancreatitis. Pancreas. 2009 Nov;38(8):890-5. 
Case Reports in Gastroenterology
Case Rep Gastroenterol 2021;15:195-201

DOI: $10.1159 / 000511286$

(c) 2021 The Author(s). Published by S. Karger AG, Basel www.karger.com/crg

Ergin et al.: Autoimmune Pancreatitis after a Seven-Year History of Suspicious Pancreatic Cancer

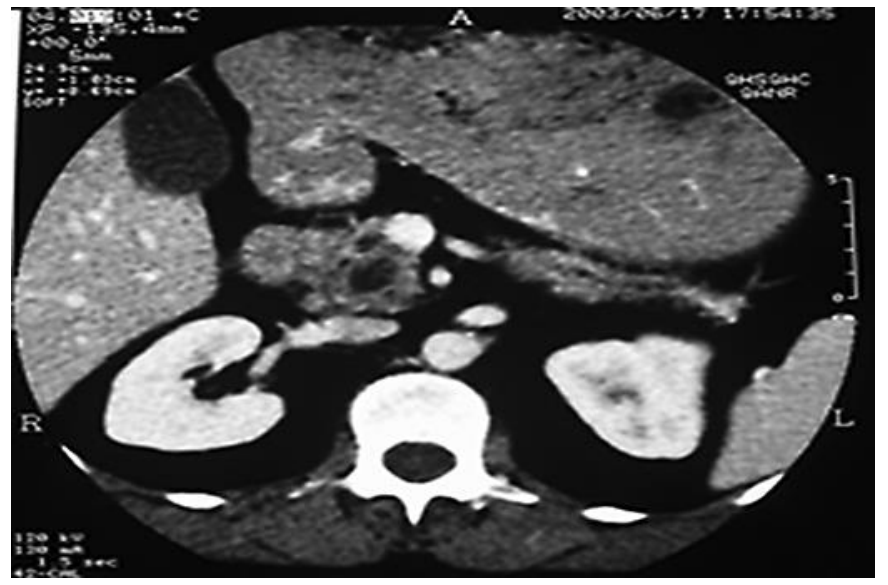

Fig. 1. The mass image on the pancreatic head detected by abdominal CT performed in 2003.

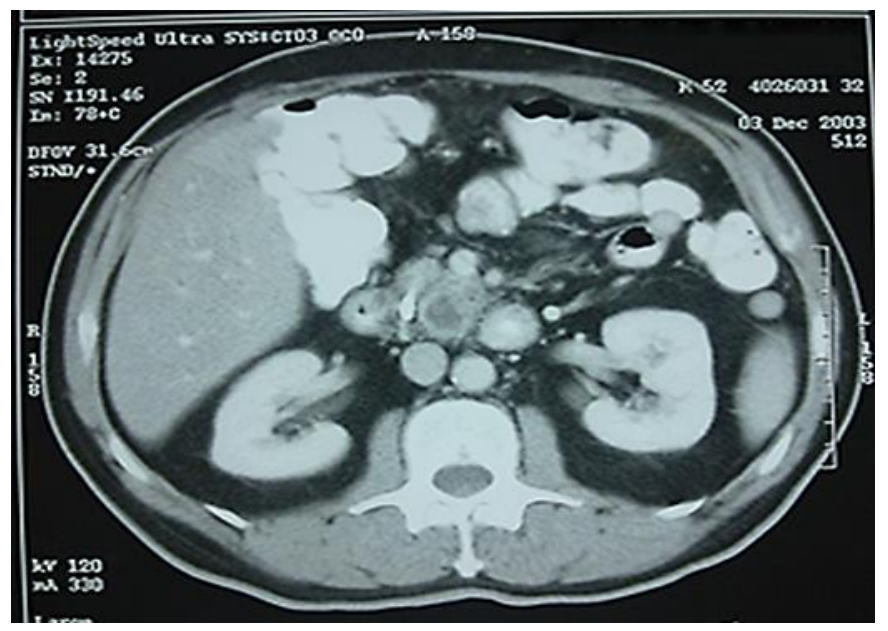

Fig. 2. The mass image on the pancreatic head detected by abdominal MRI performed in 2003. 
Case Reports in Gastroenterology
Case Rep Gastroenterol 2021;15:195-201

DOI: $10.1159 / 000511286$ (c) 2021 The www.karger.com/crg

Ergin et al.: Autoimmune Pancreatitis after a Seven-Year History of Suspicious Pancreatic Cancer

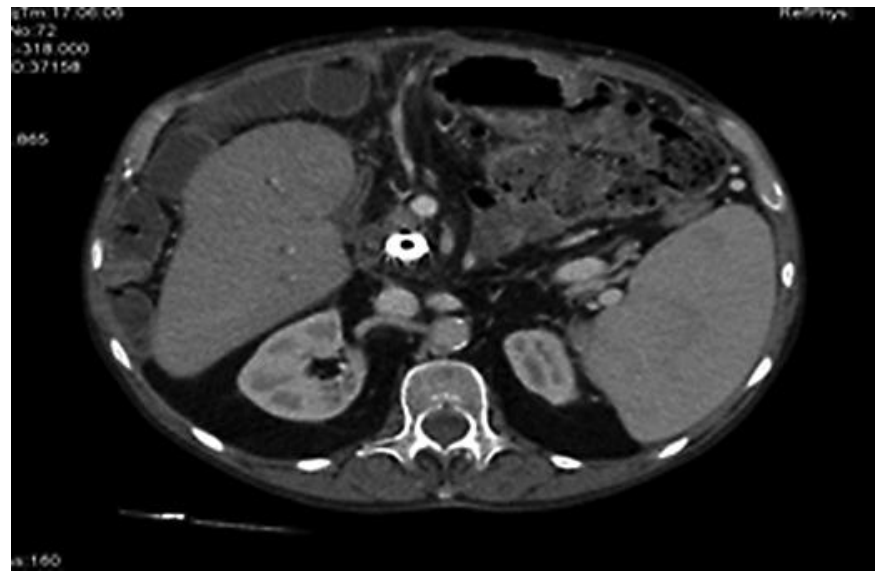

Fig. 3. A metallic stent and atrophic pancreas appearance were detected in the CT taken in 2010.

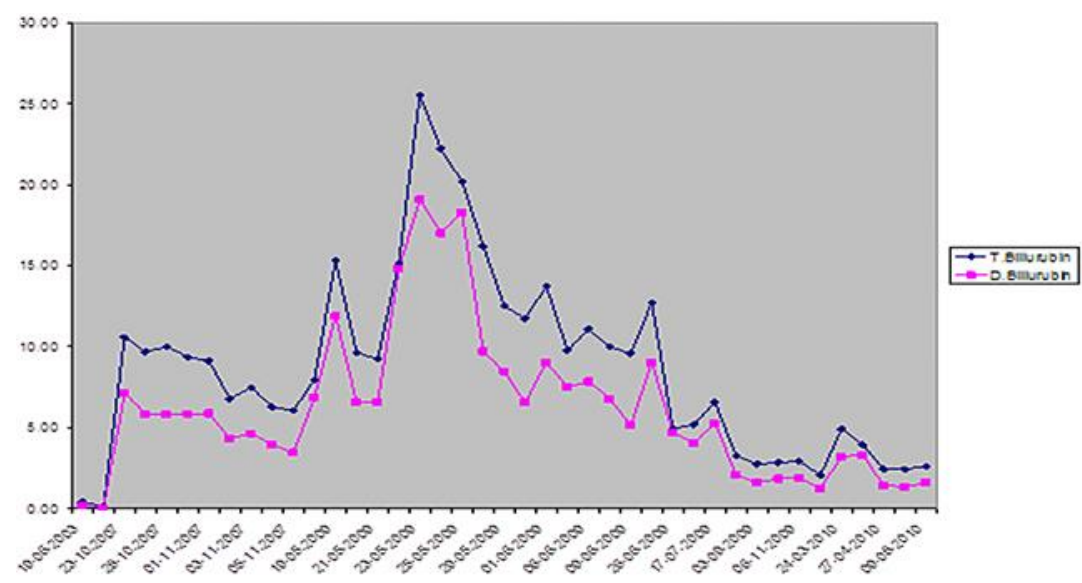

Fig. 4. Changes in total and direct bilirubin levels after steroid administration between 2003 and 2010.

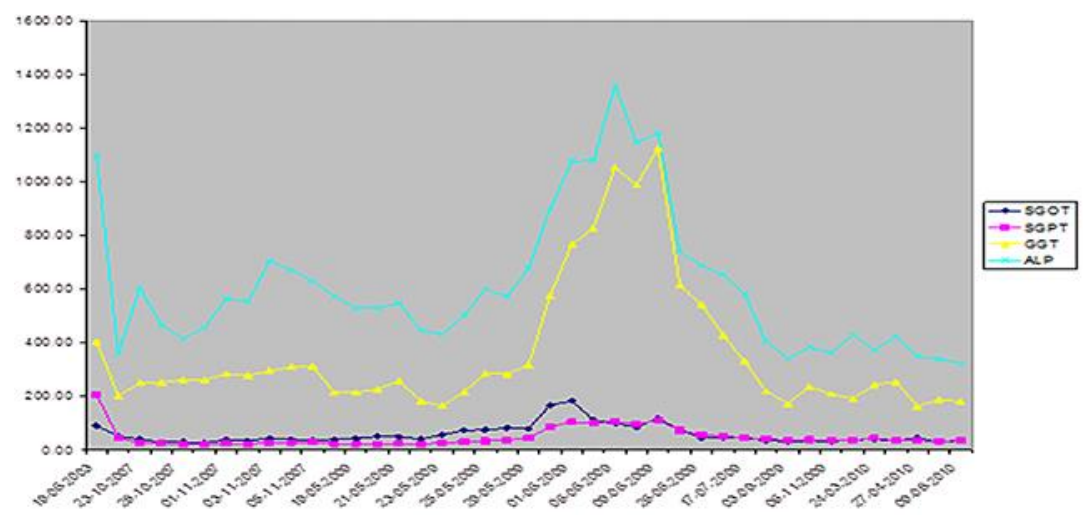

Fig. 5. Changes in transaminase and cholestasis levels after steroid administration between 2003 and 2010.

\section{Karger'}

